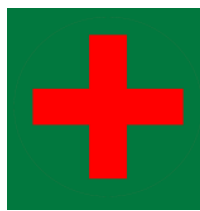

\title{
Uji Efektivitas Antibakteri Ekstrak Metanol Daun Bandotan (Ageratum conyzoides L.) Terhadap Staphylococcus aureus
}

\author{
Lovera Anggraini $^{1}$, Wahyu Margi Sidoretno ${ }^{2}$, Liza Salsabila Rifwan Putri ${ }^{3}$ \\ ${ }^{1,3}$ Farmasi, Fakultas Farmasi dan Ilmu Kesehatan, Universitas Abdurrab, Pekanbaru, \\ Indonesia \\ Email: ${ }^{1}$ loveraanggraini@univrab.ac.id
}

\begin{abstract}
Bandotan (Ageratum conyzoides L.) is a wild plant that is better known as a nuisance plant (weed) in gardens and fields. Bandotan (Ageratum conyzoides L.) has traditional properties, namely to treat infectious diseases of the skin such as boils and wounds caused by bacteria. Staphylococcus aureus is a Gram positive bacterium which is a normal flora in humans and can be pathogenic that causes infection. This study aims to determine the antibacterial activity of the methanolic extract of bandotan (Ageratum conyzoides L.) against the growth of Staphylococcus aureus at concentrations of 10\%, $20 \%$ and 30\%. This research is a laboratory experimental study to determine the diameter of antibacterial inhibition. The method used to test the antibacterial activity in this study was the agar diffusion method and chloramphenicol as a positif control. Extraction method is done by maceration method using methanol solvent. The results of the inhibition test with extract concentrations of 10\%, 20\% and 30\% could inhibit the growth of Staphylococcus aureus with the average diameter of the inhibition zones being 7,3 mm, 8,1 mm, 8,9 mm and the positive control chloramphenicol was 29,3 mm. From the results above, it can be concluded that the methanolic extract of Bandotan leaves (Ageratum conyzoides L.) has antibacterial activity against Staphylococcus aureus.
\end{abstract}

Keyword : Antibacterial activity test, Bandotan leaf (Ageratum conyzoides L.), Staphylococcus aureus

\begin{abstract}
Abstrak
Bandotan (Ageratum conyzoides L.) merupakan tumbuhan liar yang lebih dikenal sebagai tumbuhan pengganggu (gulma) di kebun dan di ladang. Bandotan (Ageratum conyzoides L.) memiliki khasiat tradisional yaitu untuk mengobati penyakit infeksi pada kulit seperti bisul dan luka yang disebabkan oleh bakteri. Staphylococcus aureus adalah bakteri Gram positif yang merupakan flora normal pada manusia serta dapat bersifat patogen yang menyebabkan infeksi. Penelitian ini bertujuan untuk mengetahui aktivitas antibakteri ekstrak metanol daun bandotan (Ageratum conyzoides L.) terhadap pertumbuhan Staphylococcus aureus pada konsentrasi 10\%, 20\% dan 30\%. Metode yang di gunakan untuk uji aktivitas antibakteri pada penelitian ini yaitu menggunakan metode difusi agar dan kloramfenikol sebagai kontrol positif. Metode ekstraksi dilakukan dengan metode maserasi menggunakan pelarut metanol. Hasil uji daya hambat dengan konsentrasi ekstrak 10\%, 20\%, dan 30\% dapat menghambat
\end{abstract}


pertumbuhan Staphylococcus aureus dengan rata-rata diameter zona hambatnya adalah 7,3 mm, 8,1 mm, 8,9 mm dan kontrol positif kloramfenikol adalah 29,3 mm. Dari hasil diatas dapat diambil kesimpulan bahwa ekstrak metanol daun bandotan (Ageratum conyzoides L.) memiliki aktivitas antibakteri terhadap Staphylococcus aureus.

Kata kunci : Uji aktivitas antibakteri, daun bandotan (Ageratum conyzoides L.), Staphylococcus aureus

\section{PENDAHULUAN}

Indonesia merupakan salah satu negara yang memiliki keanekaragaman hayati tinggi. Keanekaragaman hayati Indonesia menempati urutan kedua terbesar di dunia setelah Brazil. Jika dilihat dari keragaman floranya, cukup banyak jenis tumbuhan yang dimanfaatkan sebagai bahan obat. Pemanfaatan tumbuhan sebagai bahan obat merupakan warisan nenek moyang sejak dahulu kala. Penggunaan tumbuhan sebagai bahan obat dikenal dengan sebutan obat tradisional (Djauhariya dan Hernani, 2004: 01).

Daun bandotan (Ageratum conyzoides L.) diketahui mengandung senyawa seperti flavonoid, alkaloid, terpenoid, steroid, minyak atsiri, dan tannin sehingga tanaman ini dipercaya memiliki banyak manfaat dan salah satunya adalah sebagai antibakteri (Sugara, 2016: 18). Secara tradisional, tanaman bandotan (Ageratum conyzoides L.) digunakan masyarakat dalam mengobati bisul dan luka yaitu dilakukan dengan cara diambil daun bandotan sebanyak tiga genggam kemudian dihaluskan dan ditempelkan pada bagian yang sakit dan dibalut perban, dilakukan dua kali sehari sampai sembuh (Ridayani, 2018: 02).

Infeksi kulit pada umumnya banyak disebabkan oleh infeksi bakteri. Salah satu bakteri penyebab infeksi kulit yaitu bakteri Staphylococcus aureus. Bakteri ini adalah bakteri Gram Positif yang berbentuk kokus mengelompok seperti anggur dan merupakan bakteri floura normal pada manusia yaitu pada bagian mulut, saluran pernafasan dan juga bisa menyebabkan infeksi pada kulit. Infeksi Staphylococcus aureus banyak terdapat pada selaput lendir, kulit, bisul dan luka (Dwidjiseputro, 1990 :198).

Pada penelitian sebelumnya ekstrak daun bandotan (Ageratum conyzoides L.) memiliki aktivitas antibakteri adalah penelitian yang dilakukan Ridayani (2018: 21), menyatakan bahwa senyawa-senyawa aktif dalam ekstrak etanol daun bandotan (Ageratum conyzoides L.) dapat menghambat pertumbuhan bakteri Staphylococcus aureus pada konsentrasi 40\% (13,21 mm), 55\% (14,45 mm) dan 70\% (16,70 mm). Dan pada penelitian yang dilakukan Nurhayati (2014: 05), menyatakan bahwa senyawa aktif dalam ekstrak etanol daun bandotan dapat menghambat pertumbuhan bakteri Staphylococcus aureus pada konsentrasi $25 \%$ (6,02 mm), 50\% (7,99 mm), 75\% (11,00 $\mathrm{mm})$ dan $100 \%(14,33 \mathrm{~mm})$.

Berdasarkan latar belakang dan hasil penelitian sebelumnya maka penulis ingin melakukan penelitian dengan konsentrasi yang lebih rendah dari konsentrasi penelitian sebelumnya, dan penulis ingin melakukan penelitian dengan judul "Uji Aktivitas Antibakteri Ekstrak Metanol Daun Bandotan (Ageratum conyzoides L.) terhadap Staphylococcus aureus". 


\section{METODOLOGI PENELITIAN}

Penelitian ini merupakan penelitian eksperimental laboratorium dengan menentukan diameter daya hambat antibakteri. Data yang diperoleh di analisis secara deskriptif. Sampel yang digunakan pada penelitian ini adalah daun bandotan yang diambil di kebun warga Desa Tanjung Belit Kecamatan Kampar Kiri Hulu Kabupaten Kampar. Penelitian ini dilakukan di Laboratorium Mikrobiologi dan Parasitologi Universitas Abdurrab pada bulan Februari 2021.

Alat

Alat yang digunakan dalam penelitian ini adalah beaker glass, timbangan analitik, cawan petri, autoklaf, pipet tetes, batang pengaduk, kawat ose, erlenmeyer, gelas ukur, inkubator, lampu bunsen, tabung reaksi, kaki tiga penyangga, asbes, oven, rotary evaporator, jangka sorong, pinset, pipet volume, pipet ukur dan pipet mikro.

\section{Bahan}

Bahan yang digunakan dalam penelitian ini adalah daun bandotan, aquades, DMSO (Dimethysulfoxide), $\mathrm{NaCl}$ fisiologis steril, spiritus, alkohol 70\%, cakram kosong, cakram antibiotik kloramfenikol, strain Staphylococcus aureus, media MHA (Mueller Hinton Agar), kapas steril.

\section{Pembuatan Sampel}

Sampel daun bandotan dikumpulkan, dilakukan sortasi basah yaitu pembersihan dari kotoran yang menempel pada daun yang diambil misalnya tanah, kerikil atau pengotor lainnya. Kemudian dibersihkan atau dicuci kemudian dikeringanginkan pada suhu kamar. Sampel dilakukan sortasi kering yakni memisahkan kotoran, bahan organik asing, dan sebagian simplisia rusak akibat proses sebelumnya kemudian dipotong kecil, diblender hingga halus (Soegihardjo, 2013: 10-11). Simplisia yang telah halus ditimbang sebanyak 800 gram, direndam dengan metanol dalam botol gelap. Direndam selama lima hari sambil sekali-kali diaduk, ekstrak methanol daun bandotan disaring. Kemudian diuapkan dengan menggunakan rotary evaporator hingga didapatkan ekstrak kental.

\section{Pengujian Daya Hambat}

Suspensi Staphylococcus aureus dioleskan pada permukaan media menggunakan kapas lidi steril, sampai semua bagian media rata terinokulasi. Kemudian kertas disk kosong diletakkan pada permukaan media dan diteteskan $2 \mu \mathrm{L}$ ekstrak metanol daun bandotan konsentrasi 10\%, 20\%, dan 30\% dengan diberi tekanan. Kertas disk kosong diletakkan dibagian pinggir bawah cawan petri pada permukaan media dan diteteskan dengan DMSO steril sebagai kontrol negatif (-). Kertas disk kloramfenikol diletakkan ditengah cawan petri pada permukaan media sebagai kontrol positif (+). Pengulangan dilakukan sebanyak 3 kali kemudian diinkubasi selama 1 x 24 jam pada suhu $37^{\circ} \mathrm{C}$ dan diukur zona bening yang terbentuk disekitar disk (Torar et al., 2017: 1718). 


\section{Analisis Data}

Data yang diperoleh pada penelitian ini yaitu dari diameter zona hambat. Pengukuran zona hambat dilakukan dengan menggunakan jangka sorong, dan data yang diperoleh dari hasil penelitian di laboratorium akan disajikan dalam bentuk tabel dan dijelaskan secara deskriptif.

\section{HASIL} berikut:

Berdasarkan hasil penelitian yang telah dilakukan maka didapatkan hasil sebagai

Tabel I. Hasil pengukuran diameter zona hambat ekstrak metanol daun bandotan (Ageratum conyzoides L.) terhadap Staphylococcus aureus

\section{Diameter Zona Hambat (mm)}

\begin{tabular}{|cccccc|} 
No & Perlakuan & P1 (mm) & P2 $(\mathbf{m m})$ & P3 (mm) & $\begin{array}{c}\text { Rata }- \text { Rata } \\
(\mathbf{m m})\end{array}$ \\
\hline $\mathbf{1}$ & $10 \%$ & 7,0 & 7,0 & 8,0 & 7,3 \\
$\mathbf{2}$ & $20 \%$ & 8,0 & 7,5 & 9,0 & 8,1 \\
\hline $\mathbf{3}$ & $30 \%$ & 9,0 & 8,0 & 9,8 & 8,9 \\
\hline $\mathbf{4}$ & Kontrol (+) & 31 & 29 & 28 & 29,3 \\
\hline $\mathbf{5}$ & Kontrol (-) & 6 & 6 & 6 & 6 \\
\hline
\end{tabular}

Gambar 1. Hasil pengujian daya hambat

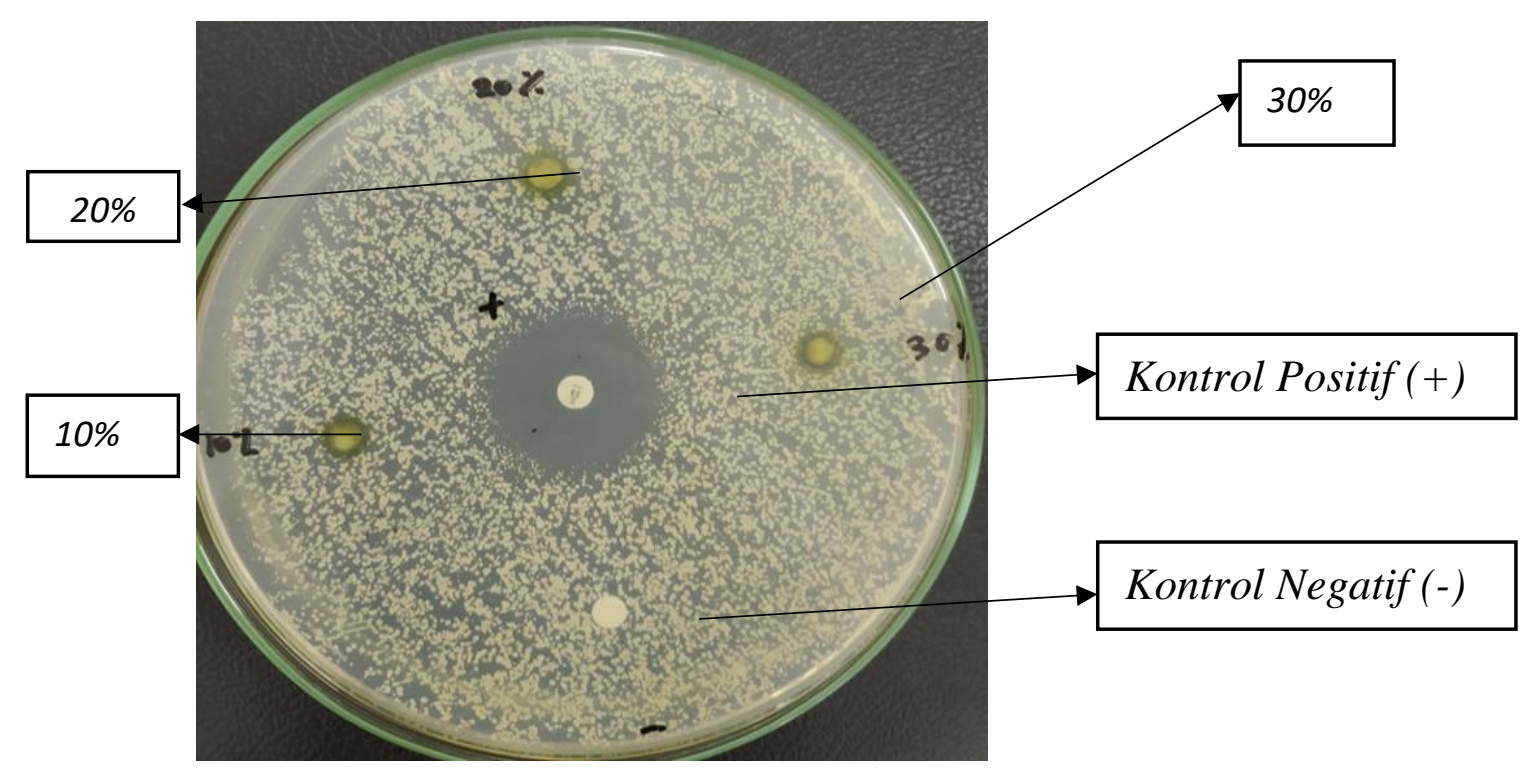




\section{PEMBAHASAN}

Penelitian ini dilakukan untuk mengetahui Aktivitas antibakteri ekstrak metanol daun bandotan (Ageratum conyzoides L.) terhadap Staphylococcus aureus. Pada penelitian ini menggunakan sampel daun bandotan (Ageratum conyzoides L.). Daun yang digunakan adalah daun yang diambil di kebun warga Desa Tanjung Belit Kecamatan Kampar Kiri Hulu Kabupaten Kampar. Daun bandotan (Ageratum conyzoides L.) yang digunakan adalah tumbuhan liar di pekarangan rumah dan juga di kebun warga Desa Tanjung Belit Kecamatan Kampar Kiri Hulu Kabupaten Kampar. Hal ini didasarkan pada penelitian yang dilakukan Ridayani (2018) dan Nurhayati (2014) dimana ekstrak etanol daun bandotan (Ageratum conyzoides L.) memiliki aktivitas antibakteri dengan konsentrasi 40\%, 50\%, 55\%, 70\%, 75\% dan 100\%.

Tahap awal yang dilakukan yaitu pembuatan simplisia daun bandotan (Ageratum conyzoides L.) yang diperoleh dengan tahap proses pencucian kemudian ditiriskan, lalu dikering anginkan pada suhu kamar. Pengeringan merupakan cara pengawetan simplisia agar tahan lama dengan mengurangi kadar air dan mencegah penurunan mutu simplisia serta untuk menghentikan reaksi enzimatik yang dapat merusak senyawa aktif yang terdapat dalam simplisia (Gunawan dan Sri, 2004: 13). Setelah proses pengeringan selesai kemudian dihaluskan dengan tujuan untuk lebih memperluas kontak permukaan bahan baku sehingga proses ekstraksi akan dapat berjalan lebih optimal (Marjoni, 2016: 18).

Metode ekstraksi yang digunakan pada penelitian ini adalah maserasi. Dipilihnya metode maserasi ini dikarenakan selain peralatan dan teknik pengerjaan yang sederhana serta biaya yang rendah, metode ini juga tidak memerlukan pemanasan yang dapat merusak zat aktif dalam sampel. Maserasi dilakukan dengan cara merendam simplisia dengan pelarut metanol. Maserasi adalah salah satu metode ekstraksi dingin. Tujuan pemilihan metode maserasi ini adalah untuk mengambil zat-zat aktif yang terdapat dalam simplisia khusus metabolit sekunder yang tidak tahan pemanasan. Pemilihan pelarut metanol dimaksudkan agar proses penguapan dapat terlaksana dengan cepat karena metanol lebih sedikit mengandung air dan memiliki titik didih yang lebih rendah dibanding etanol yaitu $64,7^{\circ} \mathrm{C}$ sehingga mudah diuapkan pada suhu yang lebih rendah. Sedangkan etanol memiliki titik didih yang relatif tinggi dibanding metanol yaitu $78,37^{\circ} \mathrm{C}$ sehingga lebih sulit diuapkan pada suhu yang lebih rendah (Marjoni, 2016: 42). Kemudian pemisahan ekstrak daun bandotan (Ageratum conyzoides L.) dilakukan menggunakan proses penyaringan sehingga didapatkan maserat yang telah terpisah dari ampasnya.

Maserat yang didapat berupa ekstrak cair kemudian diuapkan dengan rotary evaporator untuk didapatkan ekstrak kental yang selanjutnya akan dibuat larutan dengan konsentrasi; 30\%, 20\% dan 10\% menggunakan DMSO (Dimetil Sulfoksida). Pemilihan DMSO sebagai pelarut, karena pelarut ini dapat melarutkan ekstrak kental daun bandotan (Ageratum conyzoides L.) lebih baik dibandingkan aquadest. Larutan konsentrasi ekstrak metanol daun bandotan (Ageratum comyzoides L.) tersebut selanjutnya akan digunakan pada pengujian aktvitas antibakteri ekstrak metanol daun bandotan terhadap Staphylococcus aureus.

Selanjutnya yakni pembuatan media yang akan digunakan sebagai media pengujian. Media yang digunakan adalah media MHA, pemilihan media MHA (Muller Hinton Agar) karena media ini merupakan media universal yang kaya akan nutrisi untuk 
pertumbuhan bakteri serta media ini telah direkomendasikan oleh Foods and Drugs Administration (FDA) dan World Health Organization (WHO) untuk tes antibakteri (Acumedia, 2011).

Mikroba uji yang akan digunakan terlebih dahulu harus disuspensikan dalam larutan $\mathrm{NaCl}$ fisiologis hingga mencapai tingkat kekeruhan tertentu. Penggunaan larutan $\mathrm{NaCl}$ fisiologis karena $\mathrm{NaCl}$ fisiologis menyerupai cairan didalam tubuh serta untuk menjaga keseimbangan ion dari mikroba (Lestari, 2014). Suspensi bakteri kemudian disetarakan kekeruhannya dengan larutan Mc.Farland. Larutan Mc.Farland merupakan salah satu yang dapat diaplikasikan untuk menyiapkan bakteri yang akan digunakan untuk uji kemampuan mikroba. Pada pembuatan larutan Mc.Farland, setelah larutan $\mathrm{H} 2 \mathrm{SO} 41 \%$ sebanyak $9 \mathrm{~mL}$ dicampur dengan larutan $\mathrm{BaCl} 21 \%$ sebanyak $1 \mathrm{~mL}$ dalam tabung reaksi terbentuk larutan yang keruh dan menghasilkan endapan. Endapan yang terbentuk adalah reaksi antara dua bahan kimia yang bercampur yaitu endapan halus barium sulfat. Penyetaraan dengan larutan Mc.Farland dimaksudkan untuk mempermudah perhitungan bakteri satu per satu dan untuk memperkirakan kepadatan sel yang digunakan pada proses pengujian antimikroba (Sutton, 2011: 47).

Setelah suspensi bakteri mencapai kekeruhan yang sama dengan larutan Mc.Farland, kemudian suspensi bakteri tersebut dioleskan secara merata pada permukaan media dan diletakkan kertas cakram yang telah ditetesi dengan masingmasing larutan konsentrasi; 10\%, 20\%, dan 30\%. Kemudian juga diletakkan kertas cakram berisi pelarut DMSO sebagai kontrol negatif (-) dan kertas cakram antibiotik kloramfenikol sebagai kontrol positif $(+)$. Pemilihan pelarut DMSO sebagai kontrol negatif (-) dikarenakan pelarut ini digunakan sebelumnya sebagai pelarut dalam pembuatan larutan konsentrasi, dan telah terbukti tidak memberikan daya hambat pertumbuhan bakteri atau tidak bersifat bakterisidal (Pratiwi et al., 2011: 6). Pemilihan kloramfenikol sebagai kontrol positif (+) karena kloramfenikol merupakan antibiotik berspektrum kerja luas yang aktif terhadap bakteri Gram positif dan Gram negatif, baik aerob maupun anaerob sehingga dapat menghambat pertumbuhan bakteri uji yang digunakan (Sumardjo, 2009: 435). Media kemudian diinkubasi pada suhu $37^{\circ} \mathrm{C}$ selama 24 jam.

Hasil penelitian uji aktivitas antibakteri ekstrak metanol daun bandotan (Ageratum conyzoides L.) dengan konsentrasi; 10\%, 20\%, dan 30\% terhadap pertumbuhan Staphylococcus aureus dapat dilihat zona bening yang terbentuk disekitar kertas cakram setelah diinkubasi selama 24 jam. kemudian diukur menggunakan jangka sorong dengan ketelitian 0,05 mm (Sihombing et al., 2018: 47). Setelah dilakukan pengukuran dan perhitungan didapatkan hasil rata-rata diameter zona hambat dimana pada konsentrasi $30 \%$ sebesar $8,9 \mathrm{~mm}$, konsentrasi $20 \%$ sebesar $8,1 \mathrm{~mm}$ dan konsentrasi $10 \%$ sebesar 7,3 mm. Ekstrak tumbuh-tumbuhan dapat dikelompokan berdasarkan diameter penghambatan yang dihasilkan menjadi tiga kategori yaitu tinggi $(>11 \mathrm{~mm})$, sedang $(>6-<11 \mathrm{~mm})$ dan rendah $(<6 \mathrm{~mm})$ (Isnawati dan Agustina, 2018). Berdasarkan hasil rata-rata diameter zona hambat yang didapat tersebut dapat dikategorikan dalam kategori sedang karena zona hambatnya besar dari 6 dan kecil dari 11 (>6 - <11 mm).

Hasil daya hambat yang didapatakan tergolong kategori sangat rendah, hal ini dikarenakan konsentrasi yang digunakan rendah sehingga hasil zona bening yang didapatkan sedikit dan kurang terlihat jelas. Sebaiknya untuk penelitian selanjutnya dilakukan isolasi zat aktif yang berfungsi sebagai antibakteri yang terkandung dalam 
daun bandotan (Ageratum conyzoides L.) dan dibuat dengan konsentrasi yang lebih tinggi agar hasil yang di dapat lebih baik.

\section{KESIMPULAN DAN SARAN}

Berdasarkan dari hasil penelitian yang telah dilakukan, ekstrak metanol daun bandotan (Ageratun conyzoides L.) memiliki aktivitas antibakteri terhadap Staphylococcus aureus dengan rata-rata zona hambat yang dihasilkan oleh ekstrak pada konsentrasi $10 \%(7,3 \mathrm{~mm}), 20 \%(8,1 \mathrm{~mm})$ dan $30 \%(8,9 \mathrm{~mm})$. Berdasarkan penelitian yang dilakukan, penulis menyarankan agar mengisolasi zat aktif yang berfungsi sebagai antibakteri yang terkandung dalam daun bandotan dengan konsentrasi yang lebih tinggi, serta melakukan pengujian terhadap bakteri penyebab infeksi kulit lainnya.

\section{UCAPAN TERIMA KASIH}

Terimakasih penulis ucapkan kepada Prodi D-III Analisis Farmasi dan Makanan Universitas Abdurrab yang telah memfasilitasi penulis dalam menyelesaikan penelitian ini, serta terimakasih juga kepada dosen pembimbing yang turut serta membantu dalam pelaksanaan penelitian ini.

\section{DAFTAR PUSTAKA}

Acumedia. 2011. Muller Hinton Agar. PI 7101. Rev 03.

Amriani dan Lanny P. S. 2018. Uji Efek Antibakteri Ekstra Daun The (Cameliia sinensis L.) Terhadap Pertumbuhan Bakteri Escherichiae coli. Jurnal Ilmiah PANNMED Volume. 9 (3). Poltekes Kemenkes Medan.

Djauhariya, E dan Hernani. 2004. Gulma Berkhasiat Obat. Jakarta: Penebar Swadaya pratiwi.

Dwijiseputro D. 1990. Dasar-Dasar Mikrobiologi. Jakarta : Penerbit Djambatan

Gunawan, D., dan Sri Mulyani. 2004. Ilmu Obat Alam (Farmakognosi) Jilid 1. Jakarta: Penerbit Penebar Swadaya.

Isnawati, A. P., dan Agustina. R. 2018. Perbandingan Teknik Ekstraksi Maserasi dengan Infusa pada pengujian Aktivitas Daya Hambat Daun Sirih Hijau (Piper betle L.) terhadap Escherichia coli. Jurnal Farmasi Malahayati. Volume 1 (1). Lampung: Universitas Malahayati.

Lestari. 2014. Uji Daya Hidup Bakteri Asam Laktat Sebagai Kandidat Probiotik Pada Beberapa Media Preparasi Air Minum Unggas. Skripsi. Lampung: Universitas Lampung.

Marjoni, R. 2016. Dasar-Dasar Fitokimia Untuk Diploma III Farmasi. Jakarta: CV. Trans Info Media.

Nurhayati, E. P. 2014. Aktivitas Antibakteri Ekstrak Etanol Daun Bandotan (Ageratum conyzoides L.) Terhadap Bakteri Staphylococcus aureus Dengan Metode Difusi Sumuran. Karya Tulis Ilmiah. Malang: Akademi Farmasi Putra Indonesia Malang. 
Pratiwi, R.S., Tjiptasurasa, dan R. Wahyuningrum. 2011. Aktivitas Antibakteri Ekstrak Etanol Kayu Nangka (Artocarpus heterophylla Lmk.) terhadap Bacillus subtills dan Escherichia coli. Jurnal Farmasi. Volume 08 (03). Purwokerto: Universitas Muhammadiyah Purwokerto.

Pratiwi, S. T. 2008. Mikrobiologi Farmasi. Jakarta: Penerbit Erlangga.

Ridayani, A. N. 2018. Uji Efek Antibakteri Ekstrak Etanol Daun Bandotan (Ageratum conyzoides L) Terhadap Pertumbuhan Bakteri Staphylococcus aureus. Karya Tulis Ilmiah. Medan: Politeknik Kesehatan Kemenkes Medan.

Sihombing, M. C. H., H. E. I. Simbala., dan A. Yudistira. 2018. Isolasi, Identifikasi Secara Molekuler Menggunakan Gen 16S Rrna dan Uji Aktivitas Antibakteri dari Bakteri Simbion Endofit Alga Padina sp. Jurnal Ilmiah Farmasi, Vol 7 No. 2. UNSRAT.

Soegihardjo. 2013. Farmakognosi. Klaten: PT. Intan Sejati.

Sugara T. H. 2016. Uji Aktivitas Antibakteri Fraksi Etil Asetat Daun Bandotan (Ageratum conyzoides L). Jurnal Ilmiah Ibnu Sina, 1(1), 88-96.

Sumardjo, D. 2009. Pengantar Kimia: Buku Panduan Kuliah Mahasiswa Kedokteran dan Program Sastra I Fakultas Bioeksakta. Jakarta: EGC.

Sutton, S. 2011. Penentuan Inokulum Untuk Pengujian Mikrobiologi. Jurnal Ilmiah, 15(3), 49-53.

Torar, G.M.J., W.A. Lolo, dan G. Citraningtyas. 2017. Uji Aktivitas Antibakteri Ekstrak Etanol Biji Pepaya (Carica papaya L.) Terhadap Bakteri Pseudomonas aeruginosa dan Staphylococcus aureus. Jurnal Ilmiah Farmasi, Vol. 6 (2). 